\title{
Periodontal treatment from the patient's perspective
}

\author{
Interview by Barbara Warnes and Louise Griffith
}

\author{
Barbara Warnes and Louise Griffith of Bristol Dental School met with Sally Ferrier and David Townsend whose \\ periodontal treatments proved life changing, to discuss their stories.
}

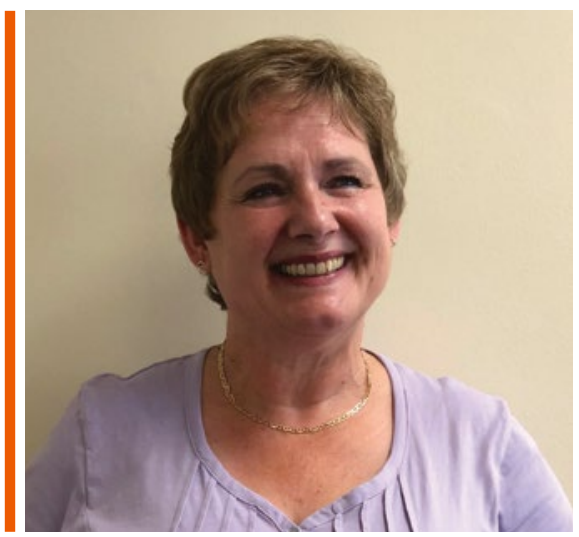

Can you tell us about the problems you were having?

I always had bleeding gums but never thought anything of it. I was constantly being told that I wasn't brushing my teeth properly, so assumed that my sensitivity and pain were due to 'teeth problems'. It wasn't until I was referred to the periodontist that I learnt that it was my gums that needed attention.

Eating was a major issue. I remember sitting having lunch with a younger colleague and carefully slicing an apple into very thin pieces, when she turned to me and said: 'isn't it funny how old people always have to cut an apple up before they can eat it?' I was 42 at the time!

But it was the sensitivity in my mouth that was the biggest concern for me. Sensitive teeth can be very glibly passed off as a minor matter, but the truth is that it can dominate the way you live your life. The first thing I used to do in the morning was to check the weather because I knew that if there was a cold wind, I would either not be able to go out or would have to wear a scarf across my face to protect myself and prevent the pain.

Sally Ferrier is a retired Learning Support Assistant, whose gums and teeth have been a problem for as long as she can remember.

What did you do to try and alleviate the problems? Can you tell us a bit about your past experiences at the dentist?

Since childhood I have regularly attended the dentist, never missing an appointment. I could never understand why I was constantly being told off for not having healthy gums and a mouth full of tartar, when, as far as I knew, I was doing exactly what I had been told. I cleaned my teeth (thoroughly as I thought) twice a day but always needed extra cleaning and plaque removal. Some dentists and hygienists were more sympathetic than others but they all implied that it was my fault and as a result, I felt guilty and a failure. I spent a fortune on electric gadgets and private hygienist appointments (as the NHS gradually shrank its provision) but still nothing got better. I lost rear teeth as there was little gum left to hold them in place and I was told that the bone had disintegrated. Again, this was all my fault because I was doing it wrong. The advice I was given was confusing and inconsistent. I should brush up and down, I should brush in circles, I should brush before a meal, I should only brush after a meal - and so it went on.

As time progressed, I continued my regular, painful visits to the dentist and hygienist but nothing really changed. I dreaded each and every visit. They can have had no idea of my terror as I sat in the waiting room having not slept for two or three nights before, dreading the sudden searing flash of pain as cold water or the prod of a hook found the point of agony. The worst part would be as I leapt upward in the chair, tears coursing down my cheek, and they said 'oh dear, that shouldn't have hurt.' Well, let me tell you, maybe it shouldn't but it really did! It reached the point where I thought about asking for all the teeth to be extracted because keeping them was proving to be such a painful experience.

So sorry to hear that you've had such upsetting experiences at the dentist. You seem much more positive about things now, what was it that changed?

The situation only began to improve about two years ago when my current lovely dentist explained I needed more help. She was very kind, very worried and I knew that she was on my side. She referred me to a specialist in the field of periodontology (I didn't even know what that meant!) and from that day on, things changed dramatically.

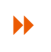


For me, the most important thing that the specialist has done was to take the time to teach me how to look after my teeth properly, and to reiterate that my problems weren't my fault. This removed a huge burden of guilt. Had I known the correct way of looking after my teeth and gums, I would have done it from the outset. Since my first appointment, I have learned that we do this as a team. She explains step by step exactly what I have to do, and my job is to do it - not just sometimes but always! She is gentle, kind and treats me like an adult not a naughty child. My treatment has involved deep pocket cleaning under anaesthetic and some surgery on a back tooth. I now go every three months to help me keep on top of things. I would be lying if I didn't admit to still being a little nervous before each appointment, but I am always ridiculously thrilled when she tells me I am doing well. Perhaps there is still something of the child in me...

\section{So, what is your current cleaning regime and have you struggled with the motivation to do it?}

I know that if I'm not spending 15-20 minutes a day cleaning, then I'm not doing it properly. So, I'll brush in the morning and then at 9 pm every evening I go up to the bathroom, put on a murder mystery audiobook and lay out all my brushes. I start with the electric brush, then the TePes - red, yellow and blue. Then I go around with the single tufted brush at the end to pick up any

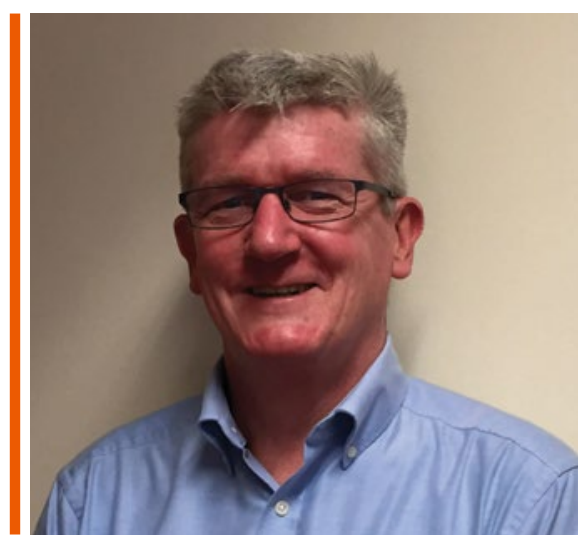

\section{Can you tell us about your first} experiences of visiting a dentist?

As a child of the 1950s (only just, 1959 to be exact!), I hated going to the dentist but was regularly taken there by my Mum. My recollection of my childhood dentist is that he bits I've left. It's become part of my routine and, seeing how dramatically things have improved, it isn't hard to stay motivated.

How have things changed for you since having this treatment and starting your cleaning regime?

My gums no longer bleed and my mouth is no longer painful. For the first time this year I bit into an apple! I no longer need numbing when I have my three monthly cleaning and the sensitivity has reduced drastically. I, myself have now become a bit of a 'gum evangelist' together. Education is so important. Over the years I have felt so guilty and hopeless about the state of my teeth.

I would suggest that the time is best spent educating. I would have paid just to have someone tell me exactly how to keep my mouth clean without going near me with the instruments. Lots of dentists seem to treat it as a practical problem and forget there is a patient attached to the set of teeth they are dealing with!

If I could offer any advice based on what I now know, I would suggest that all school

\section{'For me, the most important thing that the specialist has done was to take the time to teach me how to look after my teeth properly, and to reiterate that my problems weren't my fault. This removed a huge burden of guilt'}

and can't help spotting people who really need to sort their gums out. I have bought interdental brushes for all the family - am I popular? Probably not. Am I right? Definitely!

\section{What would be your advice to dentists managing patients with similar problems to yours?}

Firstly, don't blame, explain. Please don't just tell patients that they are brushing wrong but explain how you can solve the problem children are taught how to clean their teeth properly at school. Not just once, but regularly. This way, not only would they learn the correct way for themselves which they could take forward independently but also the message may spread at home to their families, to those who, like me have not received or understood the proper instruction across the years. This is of course a matter of finance but in the long term, must be money-saving and common sense.

David Townsend is a Regional Operations Manager and here discusses his experiences of dentists and dental practices, from a child growing up in the 1960s until now. 
What advice were you given as a child about how to look after your teeth?

None that I can remember. I was only ever taught how to look after my teeth by my

Mum and I don't remember being given any advice or instructions by my dentist. Even as a child, when a cavity was discovered, and subsequently drilled and filled, I was never taught how to look after my teeth properly.

\section{Did you ever have any problems with your teeth and gums?}

I didn't think so. I had a bit of bleeding when I brushed my teeth but I thought that this was normal. There were no TV adverts back then explaining that the bleeding wasn't right, and I wasn't in any pain, so I didn't worry.

I brushed my teeth twice a day, always with a manual toothbrush as I travelled a lot, and back then, I couldn't keep an electric toothbrush charged. It was only in 2011 when my regular dentist spotted that I had gum disease that he referred me to a specialist.

\section{What treatment and advice did the specialist give you?}

My treatment involved a thorough course of deep cleaning, half my mouth at a time, over two sessions. She could tell straight away that I was right handed (which I was very impressed by!). The most important thing I learnt was that I needed to spend more time cleaning my teeth. I was shown how to use interdental brushes properly and she made me look in a mirror to practise. I was recommended a single-tufted brush, something that I had never come across before, for the hard to reach areas at the back of the mouth. I always learn something new when I visit her and that keeps me on top of my game and inspires me to put in the effort with my cleaning regime.
What is your dental regime like now? Every evening I now use an electric toothbrush, interdental brushes at the front of my mouth, and the single-tufted brush at the back for the crowded teeth. This normally takes me about 15 minutes. In the morning, I just do a thorough clean with the electric toothbrush. I am pleased to report that the gum disease hasn't returned but I know that I have one pocket on the top right of my teeth, where brushing and using a mouthwash - which I hadn't realised before.

From your own experience, do you have any suggestions about how dentists could educate their patients about the importance of gum health?

I have personally taken inspiration from a TED talk which describes how to motivate people using the 'why, how, what' approach. In it,

\section{'I always pick up new tips and tricks about caring for my teeth every time I see the dentist, as new research generates information and knowledge moves on. Things such as leaving 30 minutes between brushing and using a mouthwash - which I hadn't realised before'}

they are packed together, that always scores a 3. I have continued to see the periodontist every four months, where I get a good oral 'MOT', the dentist every six months and the hygienist every three months. I know now that I need to keep up these regular visits to keep my teeth and gums in a good condition.

\section{What do you wish you had known or been taught by a dentist?}

Everyone is wise in hindsight, but I wish someone had taught me that I need to spend more time cleaning my teeth as I had never been given that information before. I always pick up new tips and tricks about caring for my teeth every time I see the dentist, as new research generates information and knowledge moves on.

Things such as leaving 30 minutes between the presenter explains that 'people don't buy what you do, they buy why you do it'. If people understood why they had to look after their gums and the subsequent risks to their health if they don't - such as diabetes, cardiovascular disease and stroke - then surely nobody would ever have gum problems! I really don't think I understood why my gums were so important until I met my periodontist.

I am very aware of the implications of NHS funding cuts in terms of what a dentist can achieve in a ten-minute appointment, and that changing habits is difficult. Perhaps there could be an educational campaign utilising social media to spread the message of why gum health is so important. I do think that the value of looking after your teeth needs to be explained to children so that this knowledge stays with them for the rest of their lives.

\section{BDJ RESEARCH INSIGHTS FOR ANOTHER VIEW}

- Research insights from across the BDJ Portfolio

- Providing busy readers with valuable context including article summaries and expert commentary

Catch up here: http://bit.ly/BDJResearchlnsights

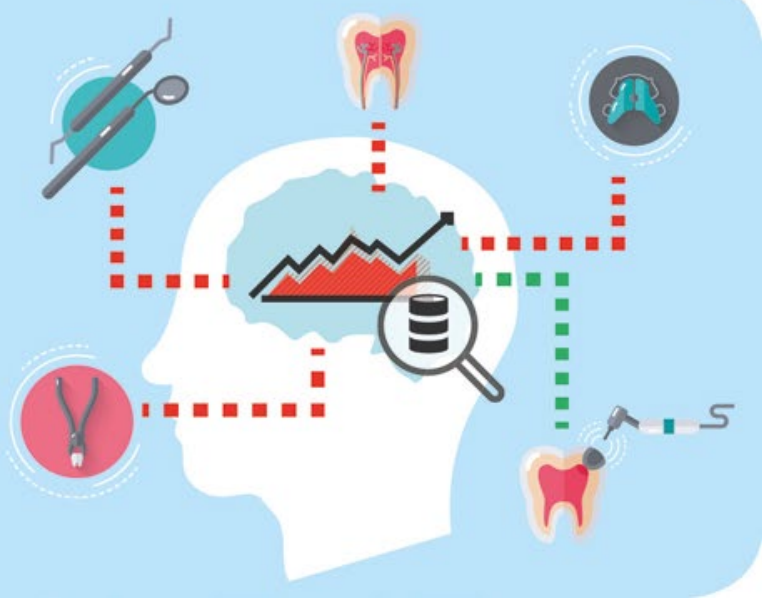

